\title{
Activa Valverde, un caso de vinculación de la sociedad civil y la Universidad contra la despoblación
}

Rufino Acosta-Naranjo, Victoria Domínguez Ruiz | Universidad de Sevilla José Antonio Domínguez Jara | Plataforma Activa Valverde

URL de la contribución <www.iaph.es/revistaph/index.php/revistaph/article/view/4464>

\section{RESUMEN}

La iniciativa Activa Valverde es un proyecto pionero y singular en la lucha contra la despoblación en Extremadura, tanto porque nace de la sociedad civil misma, como porque crece hombro con hombro con la Universidad. Ambos hechos explican la dinámica del proceso y son los que más novedosos y esperanzadores nos parecen desde la perspectiva de su posible replicabilidad y de su condición de ejemplo para otras localidades y universidades de España. Valverde de Burguillos es un pueblo de Badajoz que contaba en los años sesenta del pasado siglo XX con 913 habitantes, muy lejos de los actuales 280. Como tantos otros, afrontó a partir de los años sesenta los fenómenos hermanados de la crisis de la agricultura tradicional, la modernización del campo, la emigración rural y consiguiente crisis social y cultural. Con la emigración se desató una dinámica de fenómenos que devinieron en quiebra del sistema agrario y, así, las dehesas, tierras calmas, olivares y huertas vieron cómo llegaba el fin de su modelo tradicional. La reducción de la mano de obra en el campo tuvo una consecuencia añadida: la masculinización de la agricultura y el envejecimiento de la población activa agraria.

\section{Palabras clave}

Activa Valverde |Despoblación|Espacios rurales |Extremadura|Participación ciudadana | Valverde de Burguillos (Badajoz) | 


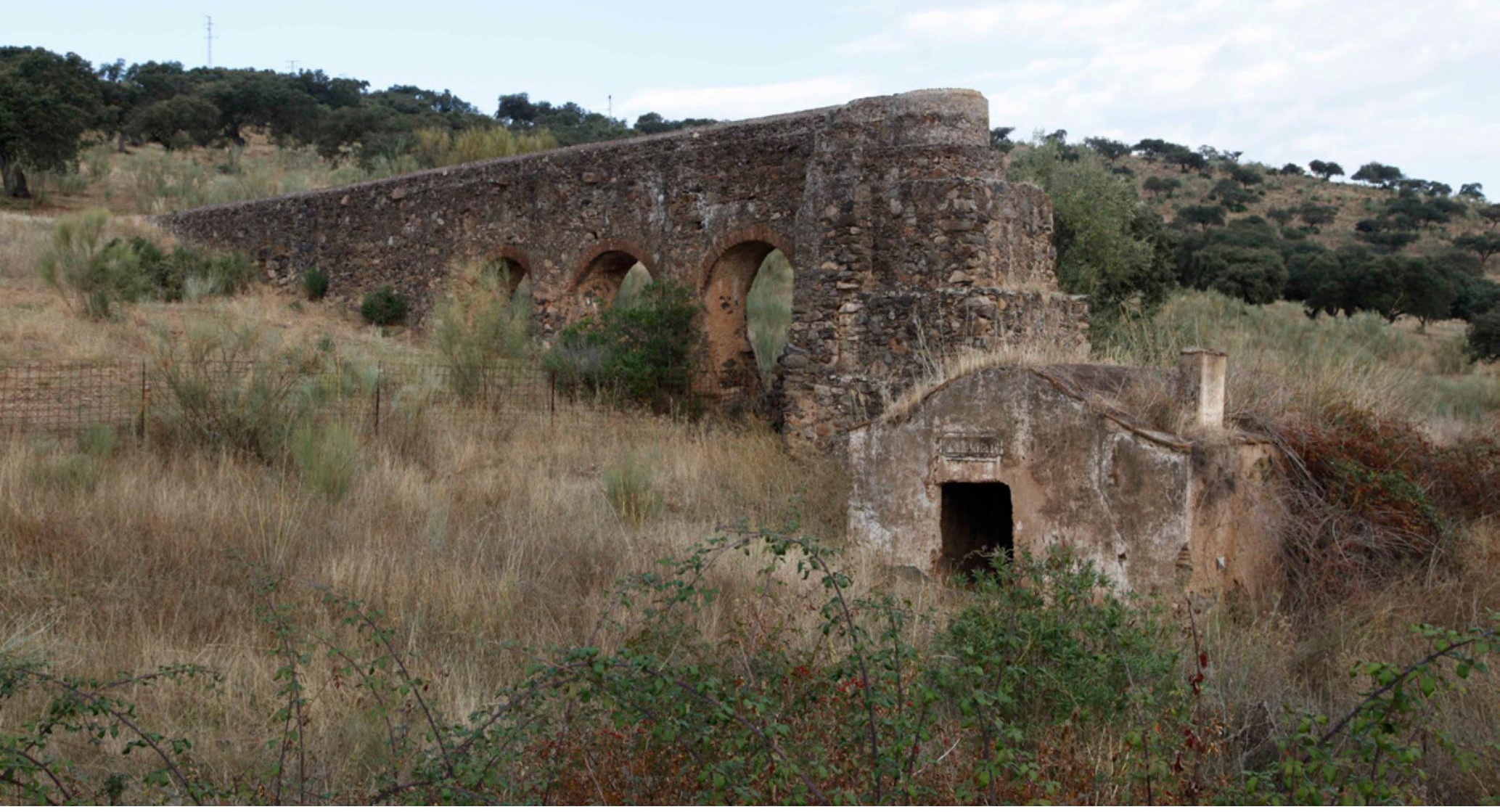

Molino del Najarrillo en Valverde de Burguillos (Badajoz) | foto Aniceto Delgado Méndez, autor de todas las imágenes del artículo, salvo que se especifique lo contrario 
La iniciativa Activa Valverde es un proyecto pionero y singular en la lucha contra la despoblación en Extremadura, tanto porque nace de la sociedad civil misma, como porque crece brazo con brazo con la Universidad. Ambos hechos explican la dinámica del proceso y son los que más novedosos y esperanzadores nos parecen desde la perspectiva de su posible replicabilidad y de su condición de ejemplo para otras localidades y universidades de España. Antes que nada hay que señalar que el grupo motor de la misma es muy reducido. Aunque hay un buen número de personas, en torno a 30, involucradas en Activa Valverde, muchas de ellas viven fuera y participan puntualmente o se relacionan a través de la página de Facebook de la iniciativa (https://www.facebook.com/ActivaValverde/), así que no pasa de la decena quienes en el día a día están realmente implicadas.

Valverde de Burguillos es un pueblo de Badajoz que contaba en los años sesenta del pasado siglo XX con 913 habitantes, muy lejos de los actuales 280. Como tantos otros, afrontó a partir de los años sesenta los fenómenos hermanados de la crisis de la agricultura tradicional, la modernización del campo, la emigración rural y la consiguiente crisis social y cultural. Con la emigración se desató una dinámica de fenómenos que devinieron en quiebra del sistema agrario y, así, las dehesas, tierras calmas, olivares y huertas vieron cómo llegaba el fin de su modelo tradicional. La reducción de la mano de obra en el campo tuvo una consecuencia añadida: la masculinización de la agricultura y el envejecimiento de la población activa agraria. Hay que tener en cuenta que la situación de la mujer en el mundo rural ha sido y es un elemento fundamental a la hora de explicar la despoblación, ya que esta última es una vía de salida en un entorno bastante limitador en todos los sentidos, puesto que su libertad personal y las oportunidades laborales y de desarrollo personal se han visto y se ven constantemente reducidas en comparación con los hombres. Detrás de la decisión de emigrar de muchos grupos domésticos está el interés de las mujeres por conseguir para ellas y su familia una situación mejor.

En definitiva, modernización, mecanización, abandono, reducción de la mano de obra y emigración son los grandes trazos que definen el marco de la agricultura y ganadería actual del municipio, que se sostiene en gran parte gracias a las ayudas de la PAC desde mediados de los años ochenta del pasado siglo y que garantiza las rentas de los empresarios agrícolas, algunos de ellos no residentes en el pueblo. Por lo que respecta al trabajo agrario asalariado, la población jornalera encontró una ayuda en los subsidios de desempleo y las obras llevadas a cabo con fondos públicos, primero el Plan de Empleo Rural, luego el AEPSA (Acuerdo para el Empleo y la Protección Social Agrarios). Estas iniciativas dotaron al pueblo, como a otros de Extremadura y Andalucía, de infraestructuras y servicios que hicieron cambiar su fisonomía y las condiciones de vida de sus habitantes, aunque tuvieran la servidumbre de generar una gran dependencia de las administra- 


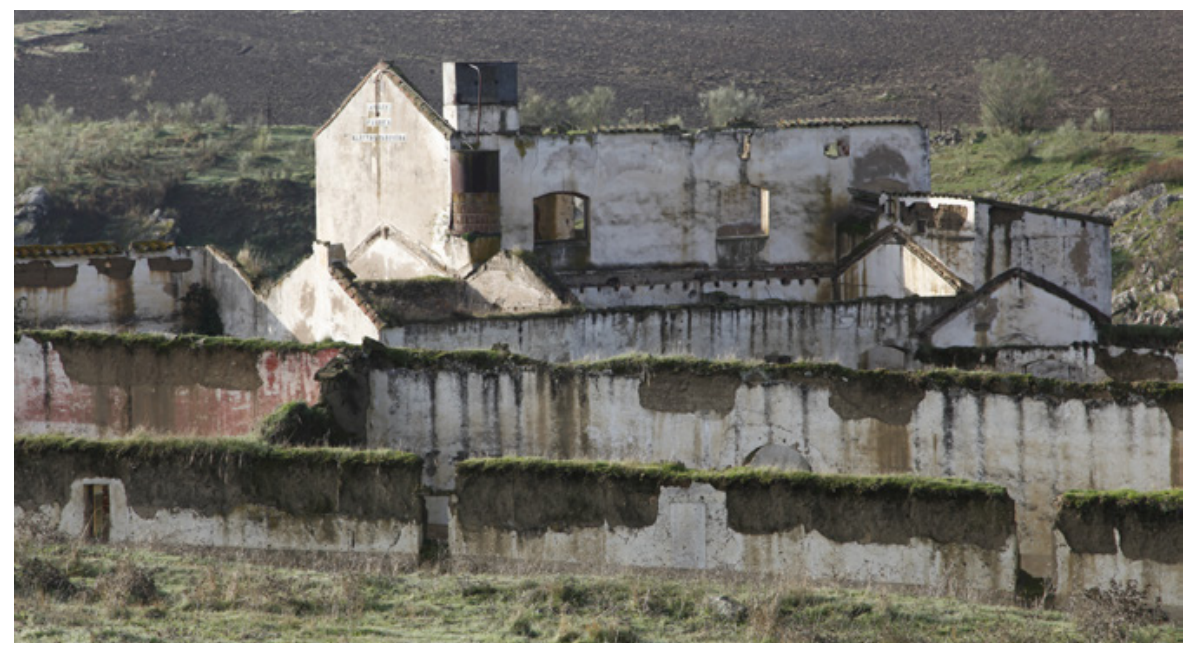

ciones e inhibición de la iniciativa, el emprendimiento y la actitud crítica reivindicativa (ACOSTA-NARANJO, 2007).

A día de hoy, la modesta industria se limita a una panadería, una envasadora de aceituna de mesa y, eso sí, un matadero de porcino que da empleo a 21 personas, de las cuales 12 residen fuera. Una tienda y un bar son los dos únicos establecimientos comerciales del pueblo. En cuanto a otros servicios, el Ayuntamiento tiene un operario de servicios múltiples y un auxiliar de policía municipal, mientras que en la escuela hay un profesor, reforzado por diferentes especialistas pertenecientes al Colegio Rural Agrupado (CRA) que comparte con otras poblaciones vecinas. No existe ningún establecimiento de turismo rural en el pueblo ni lugar para el alojamiento. La única casa de este tipo es un cortijo, próximo al casco urbano (BLASCO MARTíN, 2017).

Cuando tanto se hace referencia a que los problemas de despoblación en España tienen que ver con la falta de oportunidades, servicios, empleo e infraestructuras, conviene hacer notar a este respecto unas cuantas características del territorio. En efecto, con el desarrollo del Estado Bienestar en España y, en nuestro caso concreto en Extremadura y Andalucía, se dotó a las localidades, incluso a las más pequeñas, de un buen número de servicios e infraestructuras, entre otras cosas, debido a las obras de Plan de Empleo Rural, que no se implementó en las zonas del centro y norte del país.

En cuanto a la educación, existe una escuela en el pueblo, institutos en Zafra, a donde a diario se desplazan en autobús financiado por la administración para las y los estudiantes de Secundaria y Bachillerato. Además del consultorio local, existe un centro de salud y Hospital a $15 \mathrm{~km}$, a unos 10 minutos del pueblo. Las carreteras, en bastante buen estado, comunican con todos los pueblos de alrededor, existiendo acceso a una autovía que discu- 
Evolución de la población de Valverde de Burguillos | gráfico Elaboración propia a partir de datos del INE (ALTERACIONES, 2018)

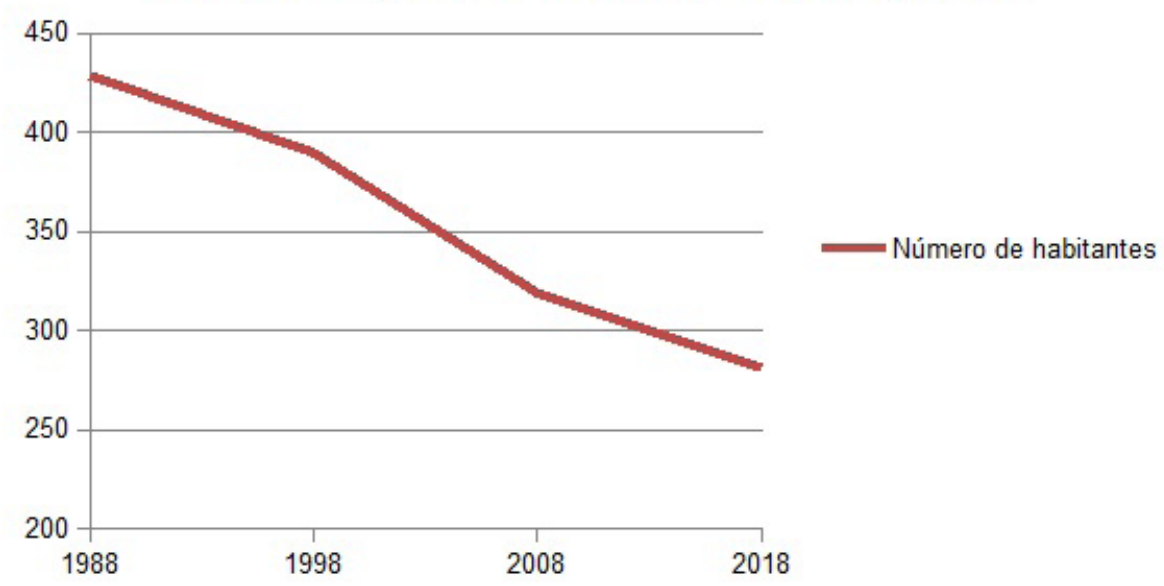

rre a 20 kilómetros de Valverde y conecta con Sevilla y Mérida. Además de agua corriente, alcantarillado y telefonía fija y móvil, el pueblo cuenta con una casa de la cultura, gimnasio, pista polideportiva, piscina, biblioteca y dos áreas recreativas, una de ellas en un embalse en el río Bodión con canoas. La Mancomunidad provee asimismo de actividades para la infancia y las personas mayores, como talleres de diverso tipo o monitores deportivos.

En lo tocante al trabajo, el nivel de paro es bajísimo, pudiéndose calificar de desempleo técnico el existente en el municipio. Incluso, como vimos, en el matadero trabaja personal de fuera. Pero nada de ello impide que Valverde se encuentre en una dramática dinámica de despoblación, como puede verse en el gráfico superior..

Según estos datos, el descenso de la población es alarmante, con un continuo retroceso en lo que va de siglo, sumado al fuerte proceso de pérdida poblacional que se había desencadenado a partir los años sesenta del pasado siglo con el proceso de modernización del país y de su campo y la consiguiente emigración.

La pirámide (ver gráfico página siguiente) nos muestra una población envejecida, con pocos efectivos en la parte inferior, indicativa de la baja fecundidad, que aboca a medio plazo a una falta de renuevo generacional. Se trata de una localidad envejecida, ya que las cohortes con mayor peso son las de mayores de 45 años. Por debajo de ese grupo observamos una fuerte reducción de efectivos. La media de edad se sitúa en los 50 años. Desde 2010 solo han nacido siete niños, mientras que el número de defunciones ha sido de 41 y han emigrado 88 personas. Entre 16 y 30 años hay 45 personas. Para este colectivo la educación se ha convertido además en una vía para la emigración, y la mayoría de quienes terminan estudios universitarios acaba emigrando. 
El cuadro que hemos descrito es bastante representativo del existente en muchos pueblos de Extremadura, salvo quizás que aquí el nivel de desempleo es menor que en muchos otros, así como su mayor su cercanía a un centro de servicios.

En este contexto es en el que surge la plataforma Activa Valverde, cuyos inicios se remontan al año 2012, en que un grupo de 20 vecinos y vecinas decide unirse para buscar soluciones a la sangría demográfica. El hecho que dispara el temor a la desaparición de la vida social es la posibilidad de cierre de la escuela, ya que cuenta solo con siete niños y niñas y se habla de su clausura. Ante ello deciden constituir informalmente una plataforma, denominada entonces SOS Valverde, reunirse periódicamente, reflexionar sobre el fenómeno y buscar posibles soluciones. En el año 2015 entran en contacto con Rufino Acosta, profesor de Antropología Social de la Universidad de Sevilla, que ha desarrollado su labor de investigación en gran parte en pueblos de la vecina comarca de Tentudía, en temas de agroecología, antropología ecológica y desarrollo rural. Empieza así una colaboración que arranca con la realización en Valverde de un Trabajo Final del Máster en Etnobotánica de la Universidad de Kent, codirigido por Rufino Acosta. A este habrían de seguir otros siete TFM dirigidos por él en los másteres de Agroecología, de la Universidad Internacional de Andalucía (UNIA)-Universidad Pablo de Olavide (UPO)-Universidad de Córdoba (UCO); Agricultura y ganadería Ecológicas, de la UNIA-UPO; y Antropología: Gestión de la Diversidad Cultural, el Patrimonio y el Desarrollo, de la Universidad de Sevilla. El mismo profesor dirigiría también dos Trabajos Fin de Grado en el Grado de Antropología

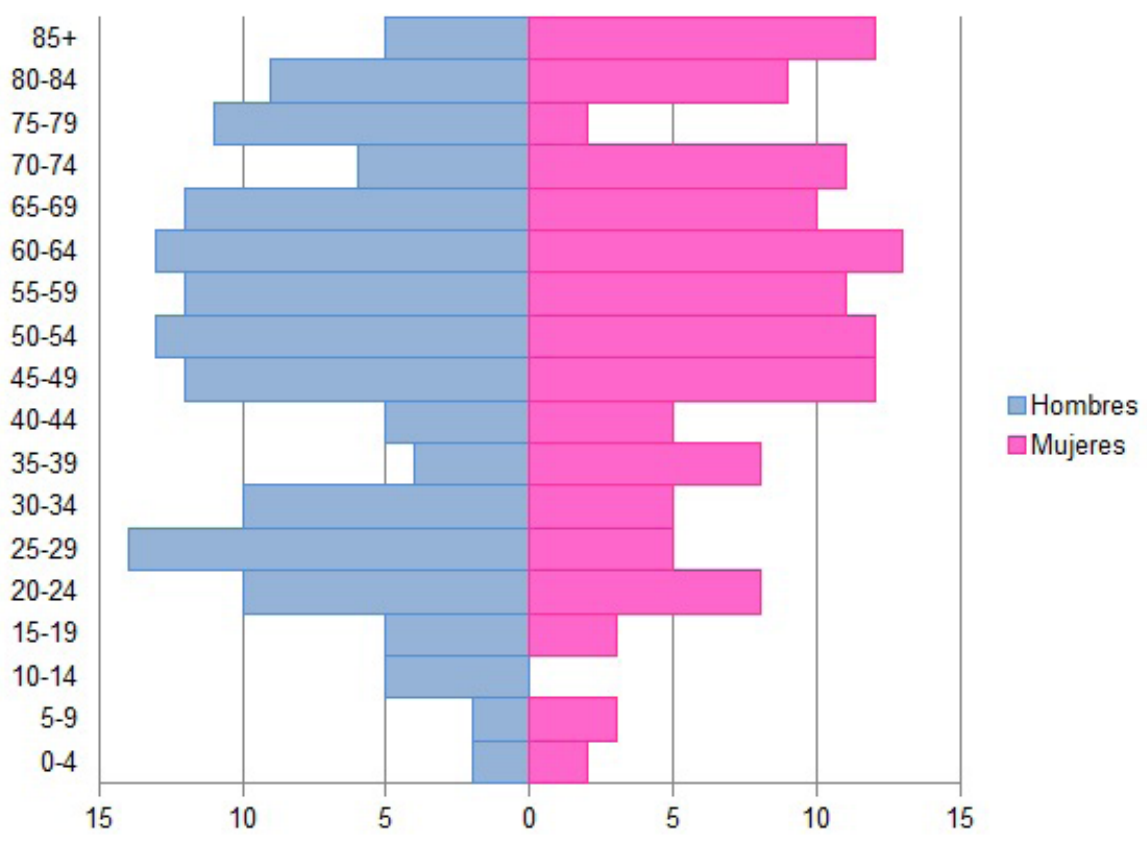


1

Ver revista PH 97 (junio, 2019): <http://www. iaph.es/revistaph/index.php/revistaph/article/ view/4375> [Consulta: 30/09/2019].
Social y Cultural de la Universidad de Sevilla. En años sucesivos se incorporó a esta iniciativa más profesorado de la Universidad de Sevilla, Victoria Domínguez Ruiz, del departamento de Construcciones Arquitectónicas I, y Julia Rey Pérez, del departamento de Historia, Teoría y Composición Arquitectónicas, ambos en la Escuela Técnica Superior de Arquitectura, que habían trabajado en temas de arquitectura vernácula, patrimonio y desarroIlo. Richard Pfeilstetter, del Departamento de Antropología, está especializado en temas de emprendimiento social y desarrollo. Estos tres últimos dirigieron TFMs del máster Patrimonio y Desarrollo, y del anteriormente referido de Antropología. Igualmente, Victoria Domínguez coorientó cuatro TFG del Grado en Fundamentos de Arquitectura y un TFM del máster Innovación en Arquitectura, Tecnología y Diseño.

Las temáticas de estas investigaciones están orientadas al conocimiento del proceso de despoblación y a la identificación de los potenciales del territorio para el desarrollo, el emprendimiento y la valorización de los recursos, como es el caso de los agroecosistemas tradicionales del entorno; el potencial para la agricultura ecológica; los recursos turísticos; la gastronomía; la memoria colectiva; la juventud rural y la despoblación; las plantas alimentarias y medicinales silvestres; los migrantes y refugiados como potenciales repobladores; las dinámicas rural-urbano y la despoblación; el patrimonio arquitectónico y urbano; y la cartografía como recurso integrador de la arquitectura vernácula con todos estos temas. Algunos de estos trabajos se insertaron en la iniciativa Vernacularmente ${ }^{1}$ de la Universidad de Sevilla.

El trabajo del profesorado y alumnado universitario, su continua presencia en el lugar y su implicación en los problemas locales, han dado como resultado un corpus de conocimientos sobre el territorio y sus gentes que ahora es la base de distintas iniciativas, para las cuales se ha tejido una red de relaciones, personales e institucionales, sobre la que edificar las iniciativas contra la despoblación. Se produce por tanto una continua refacción de conocimiento entre la población local y el mundo universitario. Los trabajos del alumnado y el profesorado toman como base la información y perspectivas de la población local a través de la etnografía, que se devuelven formalizadas y son la base de iniciativas que se plantean.

En primer lugar, se ha conformado legalmente la Asociación Activa Valverde, ya que era necesario institucionalizar la plataforma, que se creó hace años, contactó con la Universidad y es el motor del proceso, para la interlocución con las diferentes instituciones y entidades con las que colaborar. Por otra parte, se ha dado visibilidad al proceso, con continuas apariciones en los medios de comunicación, a través de artículos en prensa, reportajes en la televisión regional, noticias en radio, prensa y televisión, página de Facebook, y participación de personas vinculadas a la iniciativa en diversos encuentros de ámbitos regional y nacional, como las Jornadas Sin pueblo no hay 


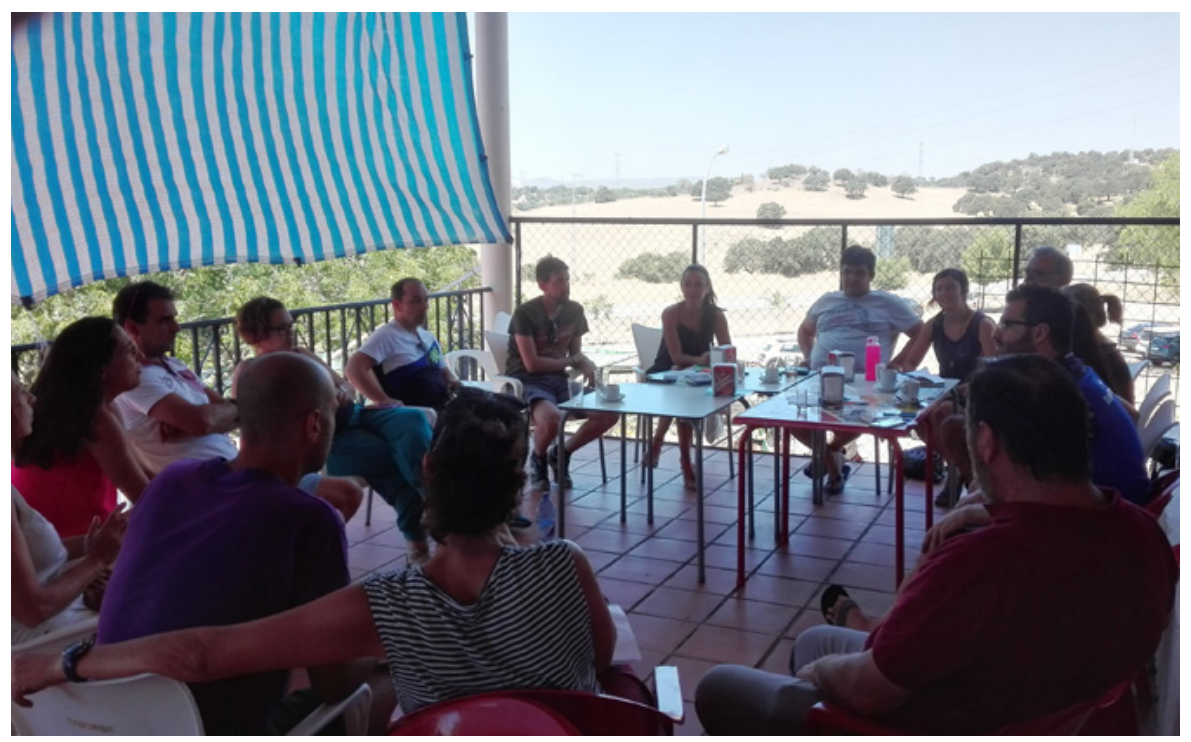

Reunión de Activa Valverde | foto Rufino Acosta

futuro, en Sevilla; el II Foro pueblos en movimiento, en Benaluaría (Málaga); el foro Reto Demográfico de Extremadura, en Caminomorisco (Cáceres); Las Jornadas sobre cultura tradicional y despoblación, en Segovia; y las III Jornadas Valdejalón por la educación, en Valdejalón (Zaragoza).

Todo ello ha dado a conocer a Activa Valverde en diversos ámbitos regionales y nacionales y ha generado expectativas sobre su desarrollo como posible modelo de referencia para afrontar el reto de la despoblación. Pero los primeros resultados han sido la implicación de las administraciones y entidades relacionadas con el tema en Extremadura. Tras diversas reuniones, visitas y participación en actividades conjuntas, se ha consolidado la relación con la Diputación Provincial de Badajoz, la Junta de Extremadura y el Centro de Desarrollo Rural (CEDER) Zafra-Rio Bodión. Con la financiación de la Diputación de Badajoz y del CEDER, el Ayuntamiento está poniendo en marcha la rehabilitación de la antigua escuela como Residencia de Estudiantes e Investigación. Además, se trabaja en la elaboración de una herramienta digital, base integradora de información de interés, como instrumento de toma de decisiones para Valverde.

Con un proyecto presentado al CEDER por Activa Valverde como entidad con personalidad jurídica propia, se propone dar continuidad a las investigaciones de las y los estudiantes, para lo cual hasta ahora se contaba exclusivamente con el apoyo del Ayuntamiento para el alquiler de vivienda donde alojarse en el periodo de trabajo de campo. Estos trabajos y los que realizan el profesorado de la Universidad de Sevilla son la base de la elaboración del Plan Estratégico contra la Despoblación en Valverde, y que será el cimiento y la guía de las posibles acciones que se implementen en el futuro. 


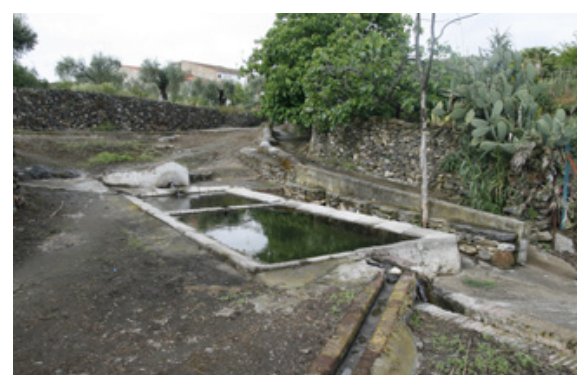

Fuente-lavadero El Charco

Como dijimos, el grupo motor de Activa Valverde es realmente reducido, en torno a unas diez personas que de manera continua están en el pueblo, participa activamente en las reuniones y está al tanto de todas las actividades, encuentros, reuniones y proyectos. Al ser dos de ellas parte de la corporación municipal, la interacción con el Ayuntamiento es continua. En la dinámica de este núcleo participa de manera directa y continua la Universidad, ya que dos de los profesores se desplazan habitualmente al pueblo y, sobre todo, están en continua relación telefónica y por redes sociales con la iniciativa, intercambiando información, haciendo circular noticias y proyectos, organizando y acompañando a reuniones, y redactando y concurriendo a proyectos. La elaboración de estrategias la toma de decisiones es conjunta, habida cuenta del altísimo grado de confianza mutua e implicación existente. En esta línea, y hasta el momento, las líneas estratégicas y proyectos que se plantean son los siguientes:

> Agroecología. La idea-guía de este ámbito es convertir Valverde en faro agroecológico de la comarca Zafra-Río Bodión, es decir, llevar a cabo iniciativas de recuperación de los manejos tradicionales o, en su defecto, de las lógicas subyacentes a los mismos, para una gestión sostenible de los agroecosistemas, para lo cual se cuenta con el trabajo que cada año lleva a cabo el alumnado del Máster Agricultura y Ganadería Ecológicas. Igualmente, se cuenta con la implicación del profesor de la Universidad de Extremadura Fernando Pulido, de la Escuela Universitaria de Plasencia, especialista en sistemas agroforestales, y de la profesora Juana Labrador Moreno, de la Escuela de Ingenierías Agrarias de Badajoz. También se dispone del apoyo

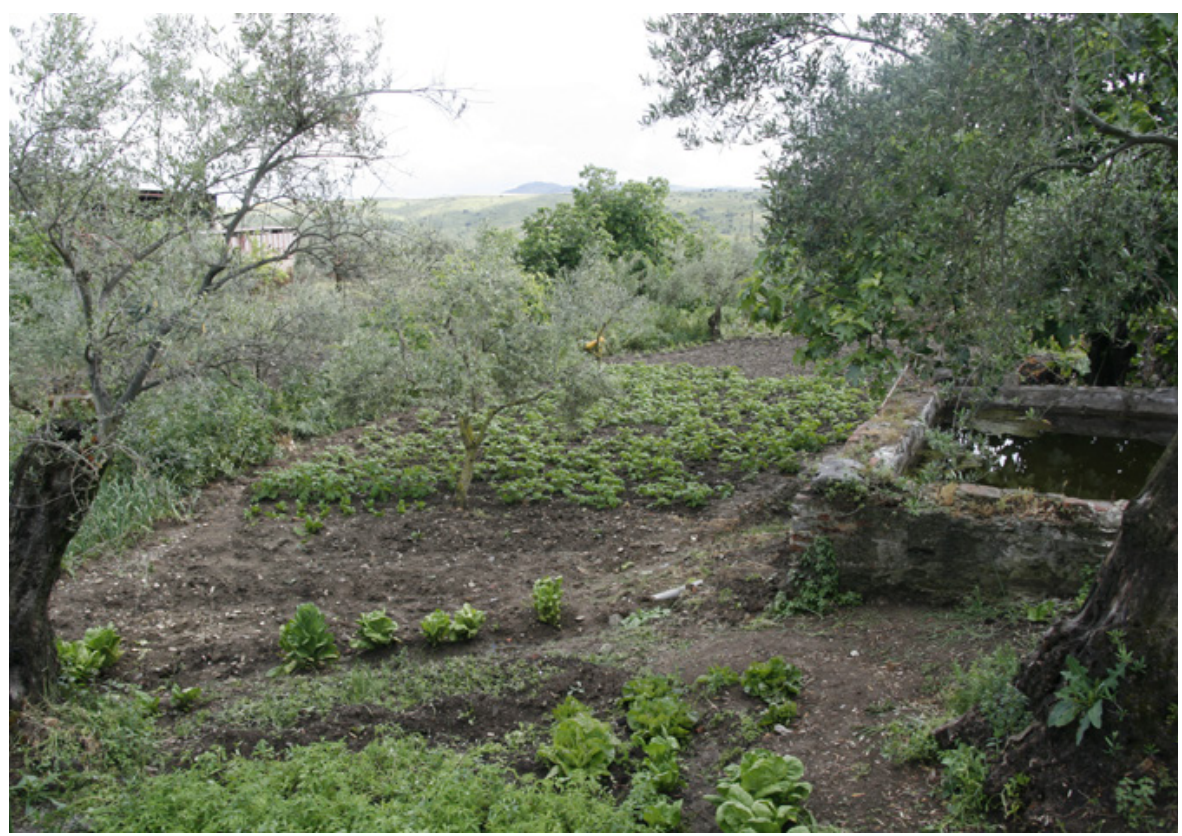


de Francisco María Vázquez, investigador del Servicio de Investigación Agraria de la Junta de Extremadura, en la finca La Orden. El potencial para la agricultura y ganadería ecológicas son objeto de estudio del alumnado de TFM y se espera poder empezar a trabajar en breve en la puesta en explotación de las huertas próximas al núcleo urbano, que han sido declaradas bien de interés etnológico/patrimonio inmaterial, como parte de la cultura del agua de Valverde. La recuperación de las variedades locales es un objetivo agroecológico, siendo de especial interés la albérchiga (melocotón), el friajón (alubia), la camuesa y el altramuz. En este mismo ámbito, se trabaja la posibilidad de desarrollar la ganadería ecológica tanto en el entorno del río

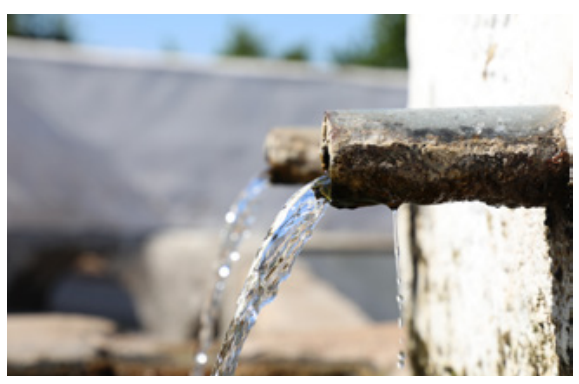

Surtidor de El Pilar Bodión como en huertos solares pastoreados por ovino.

$>$ Las plantas comestibles y medicinales silvestres. Son un potencial relevante del territorio. Sobre todas ellas destaca el espárrago, hasta tal punto que puede decirse que el área en torno a Burguillos del Cerro, Valverde y Valencia del Ventoso es la de mayor abundancia de espárragos del sur de España y en que la recolección genera una actividad económica que puede cifrarse en millones de euros, pero en la que el valor añadido es escaso, tratándose de una economía altamente informalizada. Además, en las fincas de la zona tiene lugar de manera continuada, y a veces problemática, una recolección por parte de gentes venidas de lugares muy diversos y en ocasiones lejanos, de otras regiones incluso. Se necesita por tanto la regulación del recurso y el desarrollo de una imagen de marca para una economía activadora de los pueblos. Pero además existen otras plantas con interés económico, como es el caso de diversas especies de alcachofas silvestres, bien comestibles o bien utilizables como cuajaleches, especialmente para producción ecológica y/o artesana de quesos. Otras plantas comestibles con tradición en la zona son las collejas, tagarninas, romanzas o bellotas. Una idea que va cobrando fuerza es la de conformar un grupo operativo sobre plantas silvestres entre la Universidad, el Servicio de Investigación Agraria de la Junta de Extremadura, el CEDER y empresarios de la comarca.

> Patrimonio cultural. En torno al patrimonio, tanto en su dimensión material como inmaterial, se han desarrollado interesantes trabajos de fin de titulación, habiéndose identificado, descrito e inventariado gran parte de él. Destacan la electroharinera San Luis, el molino del Najarrillo y la arquitectura vernácula en el núcleo urbano, así como otros aspectos de la vida local, cual es el caso de la gastronomía y, de manera singular, el mundo del agua, de especial interés tras la declaración como bien de interés cultural del referido conjunto denominado La Cultura del Agua. Uno de los proyectos ya en curso tiene que ver con la creación de una plataforma digital donde tiene protagonismo el patrimonio, y desde una perspectiva de endopatrimonialización y cartografía de las sensaciones y vivencias de la población local. 
$>$ La atracción de pobladores. Además de la retención de la población existente, un objetivo estratégico es el del asentamiento de nuevas personas residentes. Ante la paradoja de un territorio en despoblación y de un problema grave de personas refugiadas e inmigrantes, se plantea el asentamiento de población foránea que garantice la supervivencia del pueblo. En este sentido, se estudian posibles perfiles de nuevos pobladores y se está en contacto con diversas entidades relacionadas con personas migrantes, pensando especialmente en aquéllas con hijos e hijas provenientes de lugares en conflicto, del medio rural y conocedores del trabajo en el campo. Se ha conseguido un proyecto de la Oficina de Cooperación al Desarrollo de la Universidad de Sevilla para llevar a cabo una investigación sobre el perfil de las personas refugiadas con las que trabajan la Comisión Española de Ayuda al Refugiado (CEAR), Alto Comisariado de las Naciones Unidad para los Refugiados (ACNUR), Cruz Roja Española, y Cáritas, para conocer las posibilidades y obstáculos de la inserción de algunos de ellos en la vida de Valverde. Igualmente, a través del Ayuntamiento, se ha firmado un convenio con la Fundación CEPAIM, Convivencia y cohesión social, para colaborar en la posible elección de Valverde como lugar de residencia de mujeres migrantes, habiéndose realizado una primera visita de un grupo de mujeres con hijos a su cargo a Valverde. En fechas recientes han tenido lugar tres estancias cortas de miembros de una familia latinoamericana de ascendencia española con interés en residir en el pueblo y emprender actividades empresariales. A este respecto, uno de los principales problemas con que nos encontramos es, paradójicamente también, la falta de vivienda pues, a pesar de que en Valverde viven pocas personas, de que las casas están vacías, la realidad es que están ocupadas durante unas pocas semanas al año en vacaciones, lo que impide que estén disponibles para nuevos moradores.

$>$ La dinamización. Un proyecto de inminente realización es el de dinamización de las y los vecinos del pueblo en todo este proceso. Si bien Valverde es singular por su temprana iniciativa contra la despoblación a partir de la sociedad civil, no es menos cierto que son pocas las personas realmente activas. Eso no quiere decir que el resto del vecindario no tome parte en actividades que se organizan pero, si se quiere que se consolide un proceso ciudadano de gobernanza contra la despoblación, es preciso que haya realmente sociedad civil y capital social, como basamento de todo lo demás.

En conclusión, la iniciativa Activa Valverde es un ejemplo pionero de preocupación y respuesta ante la despoblación en el sur de España, que ya ha empezado a dar resultados concretos, y que tiene como base y singularidad que surge de las y los propios habitantes de un pueblo y de la implicación de Universidad en la lucha por una nueva ruralidad y una nueva relación del mundo académico con la sociedad civil. Todavía es pronto para valorar el proceso, que está en sus inicios, pero es una evidencia de que los pueblos están vivos y quieren seguir estándolo. 


\section{BIBLIOGRAFÍA}

- AcOStA-NARANJO, R. (2007) Dehesas de la sobremodernidad. La cadencia y el vértigo. Badajoz: Diputación de Badajoz, 2007

- alteraciones de los municipios en los Censos de población desde 1842 (2018) [en línea] Instituto Nacional de Estadística (INE), 2018 <http://www.ine.es/intercensal/ intercensal.do> [Consulta: 01/07/2019]

- BLASCO MARTíN, E. (2017) Situación actual y potencial de desarrollo agroecológico del rio Bodión y sus ecosistemas aleñados para Valverde de Burguillos. Trabajo de Fin de Máster inédito, Universidades UNIA-UPO-UCO, 2017

- ESTADÍSTICA del Padrón Continuo a 1 de enero de 2018. Datos por municipios (2018) [en línea] Instituto Nacional de Estadística (INE), $2018<$ <ttp://www.ine.es/jaxi/ Datos.htm?path=/t20/e245/p05/a2018/l0/\&file=00006001. px> [Consulta: 01/07/2019] 